\title{
The role of proteoglycans in cell adhesion, migration and proliferation
}

\section{Thomas N. Wight, Michael G. Kinsella and Eva E. Qwarnström}

\author{
University of Washington, Seattle, Washington, USA
}

\begin{abstract}
Proteoglycans comprise a part of the extracellular matrix that participates in the molecular events that regulate cell adhesion, migration and proliferation. Their structural diversity and tissue distribution suggest a functional versatility not generally encountered for other extracellular matrix components. This versatility is mainly dictated by their molecular interactions and their ability to regulate the activity of key molecules involved in several biological events. This molecular cooperativity either promotes or inhibits cell adhesion, migration and proliferation. A growing number of studies indicate that proteoglycans can play a direct role in these cellular events by functioning either as receptors or as ligands for molecules that are required for these events to occur. Such studies support a role for proteoglycans as important effectors of cellular processes that constitute the basis of development and disease.
\end{abstract}

Current Opinion in Cell Biology 1992, 4:793-801

\section{Introduction}

Adhesion of cells to their micro-environment and their subsequent proliferation and migration are regulated in part by their interaction with various components of the extracellular matrix $(\mathrm{ECM})[1 \bullet \bullet$. This regulation involves molecular interactions that govern the attachment of cells to specific ECM components, detachment of cells from these components and molecular rearrangements in the ECM that allow cells to change shape during division and/or migration. Proteoglycans (PGs) are one of the ECM components that participate in these regulatory events $[2 \bullet-4 \bullet, 5 \bullet \bullet-7 \bullet \bullet, 8 \bullet]$. Their involvement with a number of component molecules that take part in these processes is mediated either through charge interactions via the glycosaminoglycan (GAG) chains (carbohydrate-protein) or through protein-protein in. teractions via specific domains within the core proteins of the PGs. Recent reviews that stress the interactive na. ture of PGs and the role that they play in regulating cell behavior are available (Fig. 1) $[5 \bullet \bullet-7 \bullet \bullet, 8 \bullet]$.

\section{Cell adhesion}

Cells form stabilized contacts with the ECM by a complex process that depends on multiple interactions between ECM receptors and their various ligands and elements of the cytoskeleton [9]. These contacts must he hroken and reformed as cells proliferate and migrate. Proteoglycans promote cell adhesion by facilitating attachment of cells to specific ECM components (Fig. 2). For example, cell surface heparan sulfate (HS) PGs are necessary for the fomation of stable focal adhesion sites on fibronectincoated substrates $[10,11]$. Recent studies have identified a sequence within fibronectin that interacts specifically with a cell surface phosphatidylinositol-anchored HSPG in mouse melanoma cells $\left[12^{\bullet}\right]$. These observations indicate that specific classes of PGs can mediate integrinindependent adhesion events.

Expression of cell surface PGs that interact with ECM ligands appears to be critical for some cells to maintain their differentiated phenotype. S115 mouse mammary epithelial cells lose their flattened epithelial morphology and become tumorigenic when exposed to steroids. These changes are reversed when the cells are transfected with a full length cDNA to human syndecan, which is an intercalated membrane PG [13**]. The importance of syndecan in cell adhesion is further illustrated by the observation that this membrane PG is transiently expressed on pre$\beta$ - and immature $\beta$ lymphocytes when in contact with the bone marrow stroma, but is absent from circulating and peripheral lymphocytes following release from the marrow (reviewed in [7••]). As syndecan is known to exist in different polymorphic forms and bind a variety of ECM ligands (reviewed in $[7 \bullet \bullet]$ ), either transient expression and/or structural modifications in this PG may regulate the adhesion of cells to different ECMs at different times during development.

CD44 is another family of polymorphic integral membrane glycoproteins and PGs that participate in cellular adhesion $[7 \bullet \bullet, 14 \bullet \cdot$. There are both low $(80-90 \mathrm{kD})$

\footnotetext{
Abbreviations

bFGF-basic fibroblast growth factor; CS — chondroitin sulfate; DS — dermatan sulfate; ECM- extracellular matrix; GAG - glycosaminoglycan; HS - heparan sulfate; PDGF— platelet-derived growth factor; PG—proteoglycan; TGF- $\beta 1$-transforming growth factor $\beta-1$.
} 


\section{Proliferation}

Basic fibroblast growth factor Acidic fibroblast growth factor

Endothelial cell growth factor

Platelet-derived growth factor

Transforming growth factor, TGF- $\beta 1$

Transcription factors

Pleiotrophin

GM colony stimulating factor-1
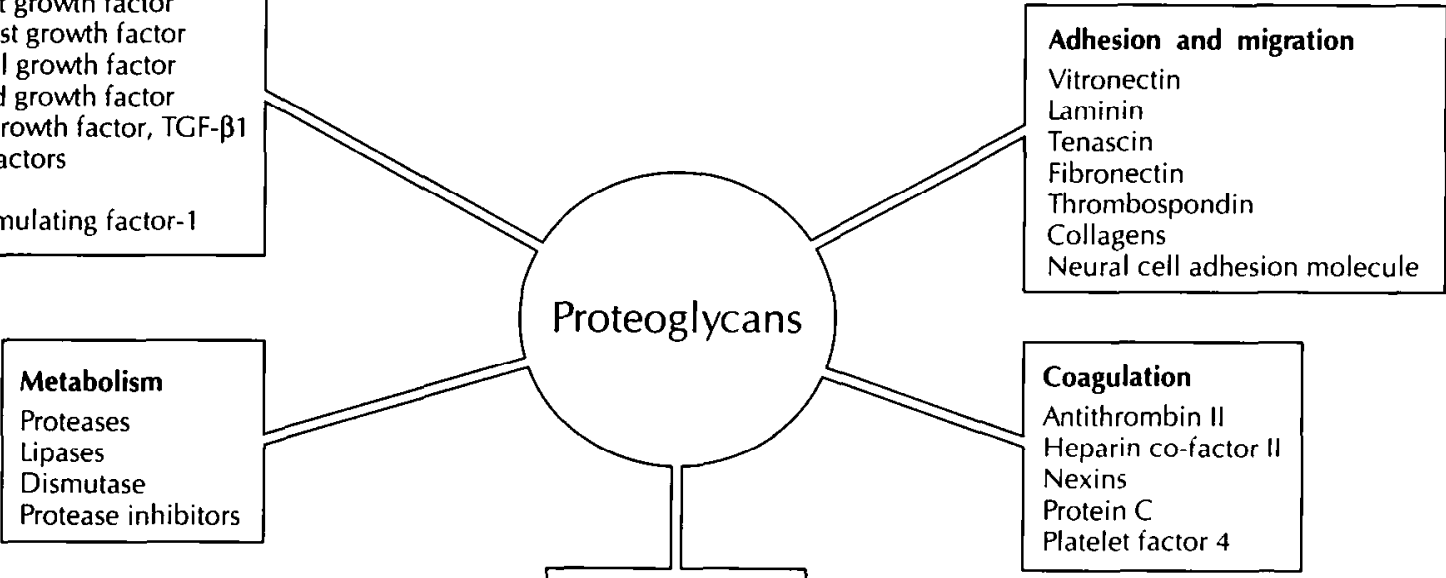

Disease

Apoprotein

Viral and parasitic

coat proteins

Amyloid

Calcium

Fig. 1. Some of the molecular interactions in which proteoglycans participate.

and high $(200 \mathrm{kD})$ molecular weight forms of CD44. The smaller form, which lacks GAG chains, predominates on lymphocytes and is responsible for the adherence of lymphocytes to the surface of high endothelial venules, a process referred to as lymphocyte homing. The high molecular weight form bears chondroitin or heparan sulfate chains and participates in cell adhesion through the ability of the GAG chains to bind ECM ligands such as fibronectin. Many cells express PG forms of CD44 that can be localized to filopodia and zones of cell contact [14**]. CD44 also contains a domain that possesses homology to the hyaluronan-binding region of cartilage link protein and the amino-terminal portion of two interstitial CSPGs, aggrecan and versican (reviewed in [7.•]). This domain allows these molecules to interact with hyaluronan, an interaction that is important in the adhesion and migration of cells in ECM enriched in hyaluronan [15,16•].

Syndecan and CD44 are members of different families of intercalated membrane PGs that have conserved cytoplas. mic domains containing potential phosphorylation sites (reviewed in [7.•]). Intercalated membrane PGs such as NG2 [17•] do not contain these specific sequences, but do contain potential phosphorylation sites. The presence of such sites has led to the suggestion that these molecules are important in signal transduction during cell adhesion.

Cell surface PGs also promote the adhesion of microorganisms to cells. Parasites such as Trypanosoma cruzi [18.] and malaria (Plasmodia) sporozoites [19*] contain membrane proteins that specifically bind heparin- or HScontaining PGs. Invasion of these parasites into cells can be blocked by competition with heparin or HS. The im. portance of surface-associated HSPG in Herpes simplex virus infection has recently been shown by demonstrating that Chinese hamster ovary mutant cells defective in HSPG synthesis are resistant to infection by the virus [20*]. Such studies point towards an important new area of investigation of clinical relevance concerning plasma membrane PGs.

Proteoglycans within the ECM or within specialized structures such as basement membranes may themselves serve as ECM ligands for adhesion. For example, the principal PG in basement membranes is a large HSPG, perlecan. Recent srudies reveal that the core protein in both mouse $\left[21^{\bullet}\right]$ and human $\left[22^{\bullet}, 2^{\circ}\right]$ perlecan contains multiple domains with homology to adhesive molecules such as laminin and neural cell adhesion molecule, suggesting perlecan may also serve as a ligand for cell surface receptors. A $38 \mathrm{kD}$ membrane protein has been tentatively identified as the cell surface receptor for this $P G$ in cultured hepatocytes [24]. In addition, a heparin-binding $78 \mathrm{kD}$ protein (moesin) [25*] has homology to a number of proteins that fonn structural links between the cell membrane and elements of the cytoskeleton. It remains to be shown whether the interaction of these membrane-associated proteins with extracellular HSPG affects adhesion and modulates the behavior of cells that synthesize perlecan or other HSPGs.

Whereas the interactions described above promote adhesion, PGs can also interfere with adhesion in several ways. PGs in the ECM may interact with other ECM adhesion ligands, such as fibronectin, and block the interaction of the ligand with its cell surface integrin receptor (Fig. 2) [8•]. The small interstitial dermatin sulfate (DS) PGs, decorin and biglycan, interact with a number of adhesive ECM ligands, either through their GAG chains 


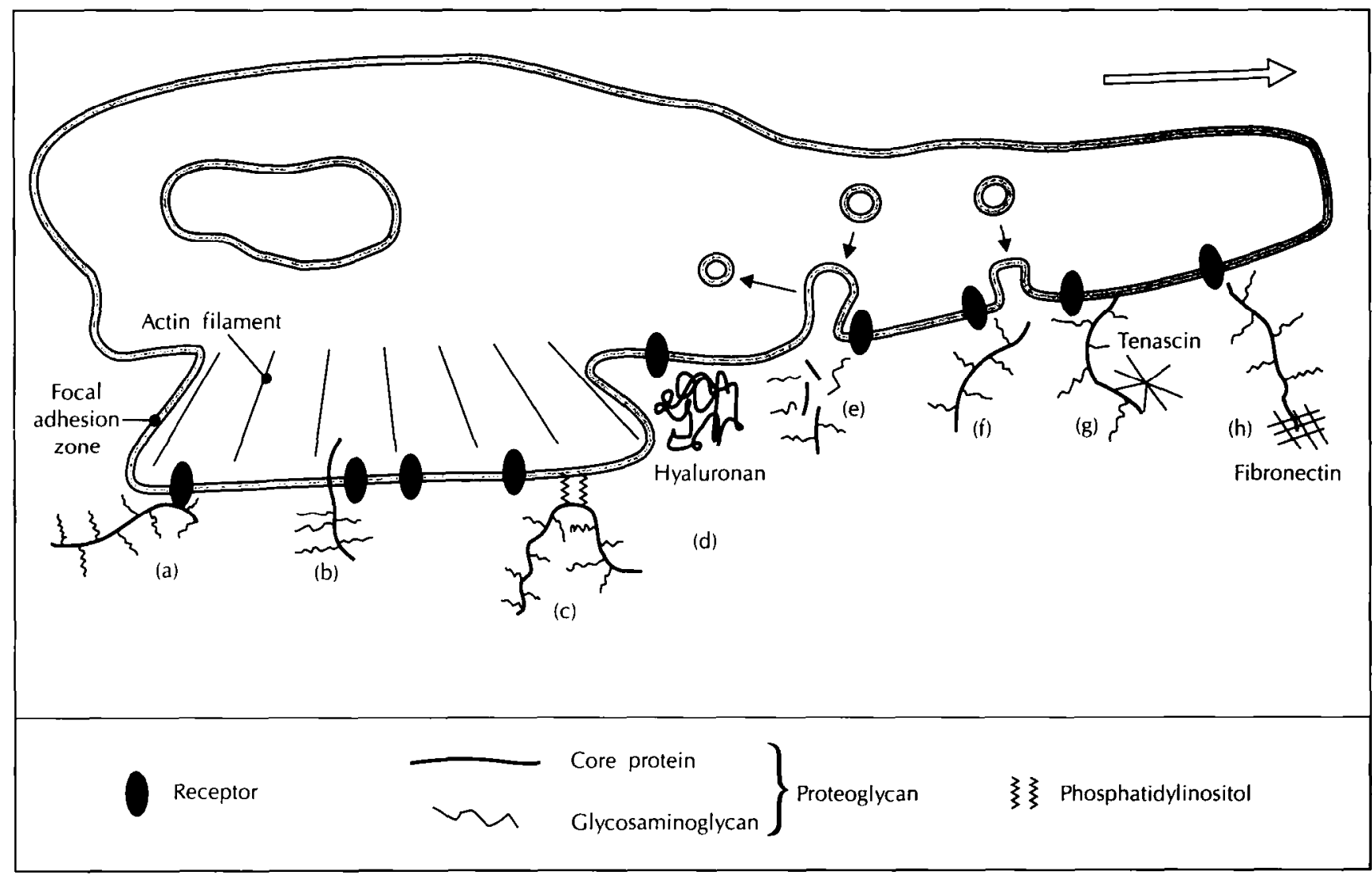

Fig. 2. Possible models in which proteoglycans (PCs) may regulate adhesive, anti-adhesive and migratory events. (a) PG as an adhesive ligand. (b) PC as a receptor for an adhesive ligand. (c) PC linked to phosphatidylinositol. (d) Selective synthesis of hyaluronan to facilitate movement of the cell. (e) Secretion of proteases and glycosidases to break adhesive bonds. (f) Selective expression of PCs to create migration pathways. (g) PG binds anti-adhesive molecules such as tenascin. (h) PG binds to the adhesive ligand fibronectin preventing ligand binding to receptor.

$[26 \bullet]$, or their core proteins $[27 \bullet]$ and interfere with cell attachment. The presence of large interstitial PGs at the cell surface may prevent the interaction of cell surface receptors with their specific ECM ligands by steric exclusion [28]. In addition, cell surface associated PGs may interact with other anti-adhesive ECM molecules such as thrombospondin [29] and tenascin [30••] to destabilize cell contact points (reviewed in $[31 \cdot \bullet]$ ).

\section{Cell migration}

Adhesion sites are continually disrupted and reformed as cells change shape and move. Cell movement is also accompanied by changes in the cellular micro-environment involving the replacement of dense fibrous ECM that serves to stabilize stationary cells with a loose hy. drated micro-environment that creates pathways for cell migration. Proteoglycans and hyaluronan, a GAG that occupies large solvent domains, influence these processes. Generally, the molecules that destabilize adhesion sites (e.g. CSPGs and hyaluronan) promote cell motility, while the PGs that contribute to the formation of tight cellular adhesion sites (i.e. HSPGs) inhibit cell migration. In fact, when stationary vascular endothelial cells are induced to migrate, they switch from synthesizing an ECM enriched in HSPG to an ECM enriched in CS/DS PG [32].
The importance of CSPGs in cell migration is well established. Removal of CSPG from the surface of mouse melanoma cells or inhibition of CSPG synthesis by these cells prevents their migration and invasion into type I collagen gels without affecting adhesion to a collagen substratum [33॰]. The cell surface PG responsible for this activity is a CSPG whose core protein is immunologically related to CD44. Furthermore, a spliced variant of CD44 is selectively expressed in metastasizing rat carcinoma cells and is capable of conferring metastatic behavior to non-metastasizing carcinoma cells [34*•]. Although CD 44 is not expressed by all cells during migration, other cell surface PGs may serve a similar role. For example, in the healing of cutaneous wounds, the migrating and proliferating epithelial cells and endothelial cells forming new blood vessels show increased expression of syndecan [35.]. While changes in specific PGs are associated with the onset of cell migration, the precise mechanism by which PGs influence this cellular event is not understood.

Although certain PGs facilitate or promote cell migration in some systems, other PGs inhibit or establish barriers to migrating cells. For example, regions enriched in CSPG in the developing mammalian retina exclude advancing growth cones [36**]. Removal of CSPG from these regions results in new axonal growth. Localized 
accumulation of CSPG also correlates with restriction of neural crest cell migration in developing chick embryos [37•]. In another model of axonal guidance, axonal extensions of dorsal root ganglia avoid contact with explants of epidermis in co-culture [38•]. Inhibition of CSPG synthesis with $\beta$-xyloside, or incubation of the co-cultures with anti-CSPG antibodies, results in contact between extended axons and epithelial explants, abolishing avoidance of contact that is seen in control cultures. Also consistent with the conclusion that CSPGs delimit the pathways of neuronal outgrowth is the observation that CSPGs isolated from rat brain inhibited nerve growth factor-induced neurite extension when bound to pheochromocytoma cells [39॰]. Thus, it may be that PGs function as 'avoidance' molecules in the nervous system by acting as steric blockers for receptors in the growth cone of elongating axons (discussed in [31••]). Two recent papers, however, suggest novel mechanisms by which matrix PGs may influence cell migration. For example, HS and CS significantly increase activation of plasminogen by urokinase-type plasminogen activator [40*], which has been previously localized to cell adhesive sites, where it is thought to be involved in proteolytic events that are associated with cell migration. Also, in a model of embryonic smooth muscle cell migration in the ductus arteriosus, a critical event is the penetration of cells through elastic laminae. This process may involve shedding of a cell surface elastin receptor, in a process induced by $\mathrm{CS}$ [41•].

The GAG, hyaluronan, formerly termed hyaluronic acid, also plays a role in cell migration. Although the manner in which this GAG exhibits its effect is not clear, several studies have shown an increased but transient production of hyaluronan that coincides with rapid cell migration during processes of inflammation, wound repair, tumor invasion and morphogenesis (reviewed in [16.]). Addition of hyaluronan to some cells in culture promotes their migration $[42 \bullet, 43 \bullet \bullet$, an activity that can be eliminated by removing hyaluronan with either enzyme treatments or blocking antibodies against cell surface hyaluronan-binding proteins. Thus, hyaluronanbinding proteins are required for hyaluronan to influence cell migration and they are associated with the leading lamellae of rapidly migrating cells $\left[43 \cdot \bullet, 44^{\bullet}\right]$. This family of integral membrane glycoproteins and PGs has been recently named the hyaladherins, although synonyms such as 'HAHAgrins' and 'gripabags' have also been proposed $\left[16^{\bullet}\right]$ !

\section{Cell proliferation}

Different PGs can function to either inhibit or promote cell proliferation (Fig. 3). Several laboratories have demonstrated that heparin and HS suppress the entry of cells into $S$ phase in response to some mitogens (reviewed in [45]) but the mechanism(s) remains unclear. A number of studies have addressed several possible mechanisms. For example, for some cells and mitogens, growth inhibition may involve the inactivation of the mitogen by heparin $\left[46 \cdot, 47^{\bullet}\right]$. Although heparin and HS are usually considered the only GAGs with anti-proliferative properties, DS of high iduronate content inhibits the proliferation of human fibroblasts [48*]. Such studies suggest that the uronic acid moiety in the GAG chain is important as a structural determinant for the anti-proliferative activity of these GAGs. Unusual disaccharides containing a 2 -sulfated uronate have been found in the nucleus of growth-arrested hepatoma cells [49,50], although similar structures have not been found in the nuclei of smooth muscle cells that are growth arrested with heparin [45]. The finding of GAG fragments within the nucleus suggests that GAGs might influence proliferative activity by interacting with transcription factors that are critical for cell replication. For example, heparin treatment of 3T3 cells blocks phorbol ester induction of c-myc and c-fos, two proto-oncogene products necessary for cell replication in some cells $[51,52]$. Re cent experiments suggest that heparin interferes with the activation of these proto-oncogenes by interacting with specific transcription factors, inhibiting the bind ing of these trans-acting factors to DNA [53**]. Many of the transcription factors have heparin-binding basic amino acid sequences (discussed in $[6-\cdots]$ ). These observations raise the distinct possibility that GAGs may, under some circumstances, regulate gene activity at nu. clear sites.

Proteoglycans may also function as mitogens. The $80 \mathrm{kD}$ subunit of colony stimulating factor-1 (CSF-1) contains a single chain of $C S\left[54^{\circ}\right]$. This PG regulates the proliferation and differentiation of mononuclear phagocytic cells in bone marrow. As CSF-1 PG possesses the same biological activity as its lower molecular weight counterpart, which does not bear GAG chains, it is unlikely that the GAG chain participates directly in growth factor activation. However, the GAG chain might permit the interaction of the growth factor with the ECM in the haemopoietic micro-environment for utilization by target cells in a manner similar to that described for the binding of other growth factors in bone marrow stroma [55,56].

Proteoglycans may also influence cell proliferation by interacting with growth factors either acting as growth factor receptors [57-] or modifying the interaction of the growth factors with their high-affinity receptors $\left[58,59{ }^{\bullet}\right]$. Such interactions are believed to induce conformational changes in the growth factor [60.] or possibly in the growth factor receptor, perhaps involving dimerization, such that high-aftinity interactions between ligand and receptor are possible. Removing HS from the surface of $3 \mathrm{~T} 3$ cells and skeletal muscle myoblasts dramatically reduces the binding of basic fibroblast growth factor (bFGF) to these cells [61•] while leaving the mitogenic activity of other growth factors such as of platelet-derived growth factor (PDGF) and epidermal growth factor unaffected. Recent studies indicate that HS chains contain a specific carbohydrate sequence in which $\mathrm{N}$-sulfate groups and iduronate-2-sulfates are essential for binding of bFGF $[62 \bullet]$. This is in contrast to the binding of transforming growth-factor (TGF)- $\beta 1$ to the PG component of the TGF- $\boldsymbol{\beta}$ receptor, betaglycan, in which the GAG chains are not required $\left[63,64^{\circ}\right]$. These different binding sites allow for the binding of more than one growth factor to the same PG [65•].

Proteoglycans may also sequester growth factors in the ECM in a form protected from proteolysis $[66 \bullet \cdot, 67]$ and thereby regulate their availability and/or activity. Release 


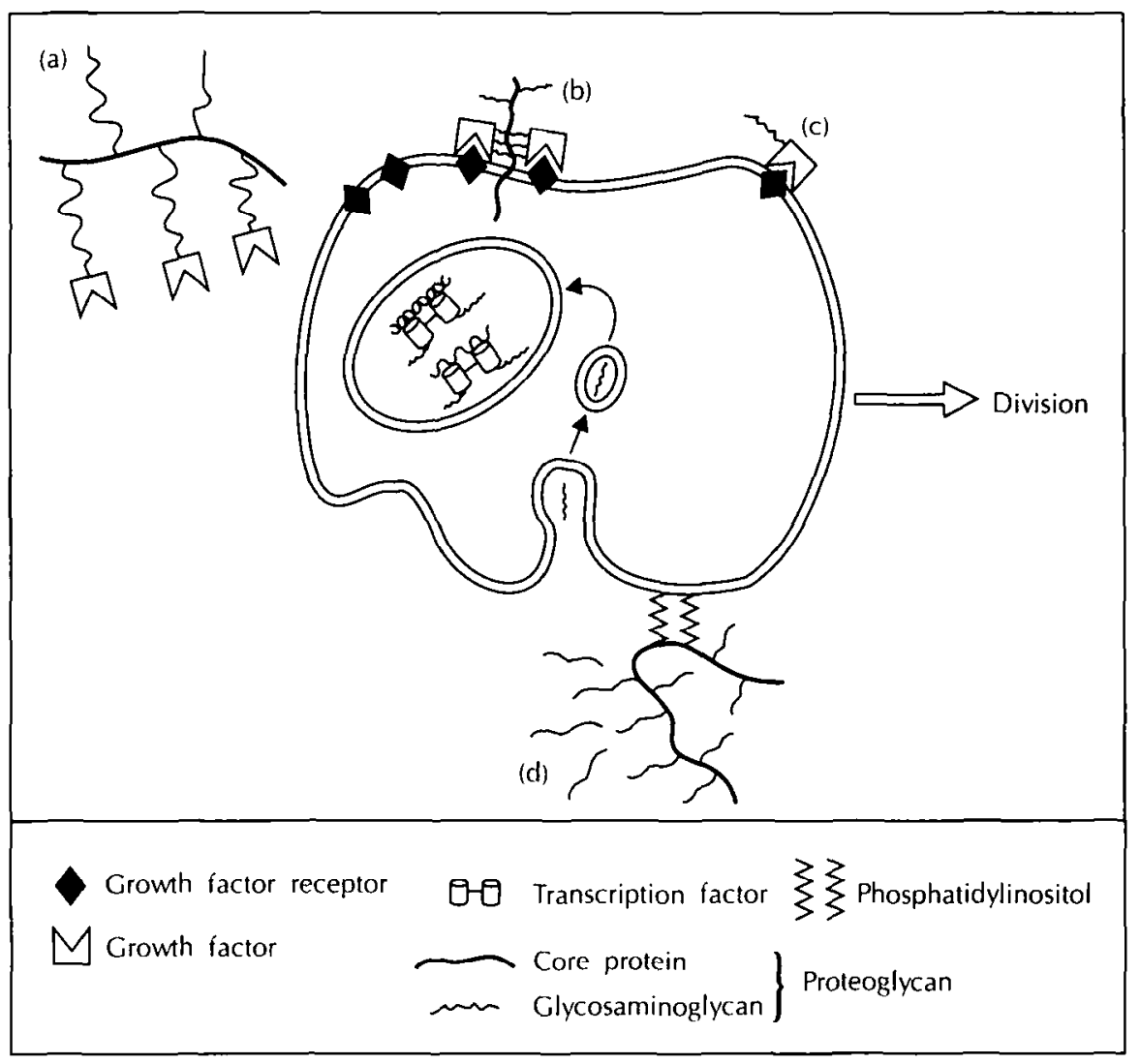

Fig. 3. Proposed mechanisms in which proteoglycans (PCs) may participate in the regulation of cell proliferation. (a) PG binds growth factors in the extracellular matrix. (b) PC as a membranebound facilitator in high-affinity binding of growth factors to their receptor. (c) PC as a mitogen. (d) Processing of phosphatidylinositol-linked PG to generate growth inhibitory glycosaminoglycan (CAG) fragments, which are internalized. CAC binds to nuclear transcription factors, which inhibits their activity. of the growth factor-PG complex could occur by the ac. tion of proteases, glycosidases or phospholipases [68*] made available during events associated with development, tissue injury and formation of new blood vessels $[69,70]$. Support for an effect by PGs on growth factor activity comes from snudies that demonstrate that the small interstitial DSPGs, decorin and biglycan, can inactivate the mitogenic activity of TGF- $\beta 1$ [71]. Interestingly, TGF- $\boldsymbol{\beta} 1$ stimulates the synthesis of these small DSPGs in some cells (reviewed in $\left[8^{\bullet}\right]$ ), and this reciprocal relationship may be one way in which specific PGs regulate the activity of growth factors.

Cell proliferation is often accompanied by the selective expression of specific PGs. For example, syndecan is expressed by proliferating cells in the mesenchyme during tooth bud morphogenesis [72•]. In addition, the stimulation of arterial smooth muscle cell proliferation by PDGF is accompanied by specific changes in the transcription/translation and post-translational processing of versican, which is a principle PG present in blood vessels [73•]. Although the relevance of these changes to the growth state of the cell is not yet understood, such modifications in specific PGs may alter the binding characteristics of the micro-environment surrounding cells affecting growth factor availability and/or activity. It should be emphasized that although increased PG synthesis is correlated with cell proliferation, induction of PG synthesis does not always appear to be a prerequisite for cell proliferation as interruption of PG synthesis by $\beta$. $D$-xylosides can be uncoupled from the anti-proliferative effect of this molecule $\left[74^{\bullet}, 75^{\bullet}\right]$.

\section{Conclusion}

We have reviewed a number of examples published within the last year that implicate PGs in the regulation of cell adhesion, migration and proliferation. While some of the evidence is still circumstantial, several studies suggest that PGs can effect the biological activity of component molecules involved in these processes through highly specific interactions. The remarkable structural diversity of the different families of PGs provides a multiplicity of ways in which these interactions can occur. The challenge for the future will be to define the nature of these molecular interactions and the biological consequence(s) of such interactions in regulating cell function.

\section{Acknowledgements}

This work was supported by NIH grants HL-18645, DE-0889 (TNW) and DE.08172 (EQ). The authors express sincere appreciation to Dr. Susan Potter-Perigo for her critical reading of the manuscript and to Ms. Barbara Kovacich for the typing of the manuscript.

\section{References and recommended reading}

Papers of particular interest, published within the annual period of re. view, have been highlighted as:

- of special interest

-. of outstanding interest

1. HAY ED: Cell Biology of Extracellular Matrix, 2nd edn. New .. York: Plenum Press; 1991.

An outstanding concise overview and up to-date account of what is new and exciting in extracellular matrix biology. Chapters are written for 
beginning students but also serve the investigator as a quick update. A 'must' for your bookshelf!

2. WIGHT TN, HEINEGARD DK, HASCAll VC: Proteoglycans: Struc- ture and Function. In Cell Biology of Exrracellular Matrix: Edited by Hay ED. New York: Plenum Press; 1991:45-78.

This review discusses the structure and function of selected classes of PGs. Emphasis is on tissue location and structure of PGs as related to function. There are several excellent illustrations as part of this review.

3. HASCAL VC, HEINEGARD DK, WIGHT TN: Proteoglycans:

- Metabolism and Pathology. In Cell Biology of ExtracelIular Matrix Edited by Hay ED. New York: Plenun Press; 149-175.

This review summarizes current concepts and problems concerning biosynthesis, catabolism and pathology of PGs. Excellent diagrams and illustrations facilitate the understanding of some of the complexities associated with these topics.

4. Hardingham TE, Fosang Aj: Proteoglycans: Many Forms and - Many Functions. FASEB J 1992, 6:861-870.

A concise and well written summary that emphasizes the structure of the different domains of the core proteins of several PGs and how these domains influence PG function.

5. KJELLEN L, LINDAHL U: Proteoglycans: Structures and Interac-. tions. Annu Rev Biochem 1991, 60:443-475.

A comprehensive, detailed and up to-date account of how the structure of the GAG chains and the core proteins of PGs influence the binding capacity and function of these molecules. The authors give considerable attention to the importance of the GAG chains in defining the interac. tion of the PGs and this coverage is often lacking in other reviews. An extensive bibliography is included.

6. JACKSON RL, BUSCH SJ. CARDIN AD: Glycosaminoglycans: -. Molecular Properties, Protein Interactions and Role in Physiological Processes. Plysiol Rev 1991, 71:481-539.

A detailed and thorough up-to-date summary of evidence indicates that a key biological property of PGs is their ability to form specitic associ. ations with critical molecules involved in several biological processes. More than 550 references are cited and this review is an excellent re source for those investigators interested in PG interactions.

7. Jalkanen M, JalKanen S, Bernfield M: Binding of Extracel-. lular Molecules by Cell Surface Proteoglycans. In Biologv of Extracellular Matrix: Receptors for Extracellular Matrix: Orlando: Academic Press; 1991:1-37.

An excellent current account of cell surface PGs that function either as ECM receptors or as growth factor receptors. Considerable attention is given to the concept that several different cell surface PGs share structural features that implicate these molecules in signalling events associated with specific ligand interactions. Consideration is also given to evidence that indicates individual classes of PGs undergo structural modifications during morphogenic events, which may lead to altered PG function.

8. RuOSlahti E, Yamaguchi Y: Proteoglycans as Modulators of Growth Factor Activities. Cell 1991, 64:867-869.

A short review that stresses the importance of PG interactions with growth factors as potential regulators of the growth of specific cells in several different systems.

9. AKIYAMA SK, NAGATA K, YAMADA KM: Cell Surface Receptors for Fxtracellular Matrix Components. Biachim Bioplyss Acto $1990,1031: 91-110$.

10. WOODS A, COUCHMAN JR, JOHNSSON S, HOOK M: Adhesion and Cytoskeleton Organization of Fibroblasts in Response to Fibronectin Fragments. EMBO J 1986, 5:665-670.

11. LEBARON RG, ESKO JD, WOODS A, JOHNSSON S, HOOK M: Adhe. sion of Glycosaminoglycan - Deficient Chinese Hamster Ovary Cell Mutants to Fibronectin Substrata. / Cell Biol 1988, 106:945-952.

12. DRAKE SL, KIFIN DJ, MickFLSON DJ, OfGeMa TR, FI RCHT I.T

- MCCARTHY JB: Cell Surface Phosphatidylinositol-anchored Heparan Sulfate Proteoglycan Initiates Mouse Melanoma Cell Adhesion to a Fibroncctin Derived Heparin-binding Synthetic Peptide. J Cell Biol 1992, 117:1331-1341.
The importance of this paper lies in the demonstration that melanoma cells adhere to the heparin binding domain of fibronectin by at least two mechanisms - one that involves a phosphatidylinositol-linked HSPG while the other involves non-RGD-dependent integrin ( $\alpha 4 \mathrm{~B} 1$ ).

13. LEPPa S, MaLj M, MietTinen HM, Jalkanen M: Syndecan Ex- pression Regulates Cell Morphology and Growth of Mouse Mammary Epithelial Tumor Cells. Proc Natl Acad Sci USA $1992,89: 932-936$

One of a few recent studies that uses gene transfer technology to demonstrate the involvement of a particular PG in the regulation of cell phenotype and growth characteristics. Such an approach is one of the most convincing ways to implicate PGs directly in regulating cellular events.

14. Brown TA, Bolichard T, ST. John T, Wainer E, Carter WG -. Human Keratinocytes Express a New CD44 Core Protein (CD44E) as a Heparan Sulfate Intrinsic Proteoglycan with Additional Exons. J Cell Biol 1991, 113:207-221.

A thorough study, which demonstrates that CD+4 is a polymorphic fam ily of related membrane PGs and glycoproteins possessing extensive di versity in both glycosylation and core protein sequence. An important aspect of this work is the demonstration that some of this diversity is generated by alternate splicing of the CD44 mRNA.

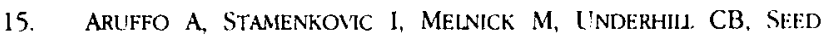
B: CD44 is the Principle Cell Surface Receptor for Hyaluronate. Cell 1990, 61:1303-1313.

16. TOOLE B: Proteoglycans and Hyaluronan in Morphogenesis - and Differentiation. In Cell Biology' of Extracellutar Matrix Edited by Hay E. New York: Plenum Press; 1991:305-341. An excellent review of the importance of PGs and hyaluronan in regu lating the behavior and differentiation of cells. Pleasant to read.

17. Nishriama A, Dahin KJ, Prince. JT, JOhstone SR, Staljclip - WB: The Primary Structure of NG2, a Novel Membrane Spanning Proteoglycan. J Cell Biol 1991, 114:359-371.

Complete sequence of a cell surface PG. NG2, from rat neural cell lines has been deduced from CDNA clones. This newly cloned PG contains a different cytoplasmic domain from other membrane PGs and is thus considered novel. Comparison of amino-terminal sequences shows that a $P G$ previously characterized as the human melanoma $P G$ is the human homologue of this PG. Sequence information will be valuable in future studies designed to investigate the role of this PG in both human melanoma and neuronal function.

18. ORTEga-Barria E. Pereira EA: A Novel T. cruzi Heparin-bind- $\quad$ ing Protein Promotes Fibroblast Adhesion of Engineered Bacteria and Trypanosomes into Mammalian Cells. Cell 1991. 67:411-421.

One of the first studies to demonstrate that a unique protein on the surface of parasites interacts with HSPGs on the surface of mammalian cells. An important contribution that addresses a new role for cell surface PGs.

19. Pancake SJ, Holt GD, Melol K S, Hoffman Sl: Malaria Sporo- zoites and Circumsporozoite Proteins Bind Specifically to Sulfated Glycoconjugates. / Cell Biol 1992, 117:1351-1357. Demonstrates that circumsporozoite proteins, which coat malaria sporozoites, contain sequences that specifically bind sulfated glycoconjugates. Sporozoite invasion into hepatocytes could be inhibited by heparin, suggesting that parasitic infection may depend on PGs. These observations have significant clinical relevance and lay the foundation for important additional studies to determine the specificity of such interactions and for additional approaches for limiting parasitic infection by targeting development of novel vaccines and drugs.

20. ShIEH M.T, WUDUNN D, MONTGOMERY RI, ESKO JD, SPEAR PG: - Cell Surface Receptors for Herpes Simplex Virus Are Heparan Sulfate Proteoglycans. / Cell Biol 1992, 116:1273-1281. Taking advantage of cell mutants defective in HSPG synthesis, these investigators demonstrated that high efficiency HSV infection is specifi. cally dependent on the presence of HSPG. As with $\left[18^{\bullet}\right]$ and $\left[19^{\bullet}\right]$, these observations have tremendous clinical relevance. The impor. tance of $P G$ in the infectivity of cells by micro-organisms constirutes a new and exciting area of biomedical research.

21. Noonan dM, Flille a, Valente $P$, Cal S, horigan E, sasaki - M. Yamada Y, Hassell JR: The Complete Sequence of Per- 

See $\left[23^{\bullet}\right]$

lecan, a Basement Membrane Heparan Sulfate Proteoglycan, Reveals Extensive Similarity with Laminin A-Chain, Low Density Lipoprotein-receptor and the Neural Cell Adhesion Molecule. J Biol Chem 1991, 266:22930-22947.

22. Murdoch AD, DOdge Gr, Cohen I, Tuan RS, lozzo RV: Pri- mary Structure of the Human Heparan Sulfate Proteoglycan from Basement Membrane (HSPG 2/Perlecan): A Chimeric Molecule with Multiple Domains Homologous to the Low Density Lipoprotein Receptor, Laminin, Neural Cell Adhesion Molecules and Epidermal Growth Factor. I Biol Chem See $\left[23^{\bullet}\right]$ $1992,267: 8544-8557$.

23. Kaluunki P, TrygGvason K: Human Basement Membrane - Heparan Sulfate Proteoglycan Core Protein: A 467-kD Protein Containing Multiple Domains Resembling Elements of the Low Density Lipoprotein Receptor, Laminin, Neural Cell Adhesion Molecules and Epidermal Growth Factor. I Cell Biol 1992, 116.559-571

These papers $\left[21^{\bullet}-23^{\bullet}\right]$ analyze the deduced amino acid sequences from cDNA clones of the extremely large core protein of the basement membrane HSPG, termed perlecan or HSPG2. These 'I lerculean' efforts reveal that this large protein contains multiple domains capable of a variety of interactions. An understanding of the structure of perlecan will help our understanding of the role of this PG in matrix assembly as well as in possibly regulating cell adhesion and migration.

24. Ciement B, Segui-Real B, hassel JR, martin GR, and yamada Y: Identification of a Cell Surface-binding Protein for the Core Protein of the Basement Membrane Proteoglycan. $J$ Biol Chem 1989, 264:12467-12471.

25. LANKES W, FURTHMaYr H: Moesin: a Member of the Protein -4.1- talin-ezrin Family of Proteins. Proc Natl Acad Sci USA $1991,88: 8297-8301$

The cloning and sequencing of this heparin-binding protein reveals an absence of a signalling and transmembrane domain and a homology to other proteins thought to function intracellularly to link the cytoskele. ton to the plasma membrane.

26. Lewandowska K, ChO HU, Rosenberg lC, Sasse J, Neame PJ, - CULP LA: Extracellular Matrix Adhesion-promoting Activities of a Dermatan Sulfate Proteoglycan-associated Protein (22K) from Bovine Fetal Skin. J Cell Sci 1991, 99:657-668. A $22 \mathrm{kD}$ protein isolated from bovine skin, which co-purifies with a DSPG, is shown to promote the adhesion of fibroblasts. The interaction of these two molecules eliminates the adhesive properties of the $22 \mathrm{kD}$ protein. This is a classic example of a PG modifying the activity of an adhesive ligand.

27. WINNEMOLIER M, SCHMidT G, KRESSE H: Influence of Decorin on Fibroblast Adhesion to Fibronectin. Eur J Cell Biol 1991, 54:10-17.

Further proof that a small interstitial DSPG can interfere with cell adhe sion by binding to adhesive ligands such as fibronectin. This paper is particularly instructive regarding the need to use caution in preparing the PG for these types of studies

28. Yamagata M, Suzukı S, aktyama S, Yamada KM, Kimata $K$ Regulation of Cell-substrate Adhesion by Proteoglycans Immobilized on Extracellular Substrates. J Biol Chem 1989 264:8012-8018.

29. MURPHY UURICH JE, HOOK M: Thrombospondin Modulates Focal Adhesions in Endothelial Cells. J Cell Biol 1989, 109:1309-1319.

30. Salmintrta $M$, Elenjus $K$, Vainio $S$, hofer U, Chiquet-. EhrismanN, THESLEFF I, Jalkanen M: Syndecan from Embryonic Tooth Mesenchyme Binds Tenascin. I Biol Chem 1991, 266:7733-7739.

An imporant observation, which reveals that syndecan isolated from mesenchyme differs in structure from syndecan isolated from epithelia. These structural differences contribute to differences in the ability of this molecule to bind tenascin. An excellent example of post-transla tional modification contributing to differences in the functional prop erties of a PG
31. SAGe EH, Bornstein P: Extracellular Proteins that Modulate -. Cell-matrix Interactions. J Biol Chem 1991, 266:14831-14834. An excellent, concise, but thorough review of the major glycoproteins that influence adhesion and migration. Although this review does not consider PGs, it is still worth reading!

32. KINSELA MG, WIGHT TN: Modulation of Sulfate Proteoglycan Synthesis by Bovine Aortic Endothelial Cells during Migration. J Cell Biol 1986, 102:679-687.

33. FaAssen Ae, Schrager JA, Kiein dJ, Oegema TR, Couchman JR, - MCCARTHY JB: A Cell Surface Chondroitin Sulate Proteoglycan, Immunologically Related to CD44 Is Involved in Type I Collagen-mediated Melanoma Cell Motility and Invasion. $J$ Cell Biol 1992, 116:521-531

Confirms recent work suggesting CD44-related antigens may bear chondroitin sulfate chains and serve as matrix receptors by binding collagen. Moreover, inhibition of melanoma cell invasion of type I collagen gels was inhibited by treatments that remove the chondroitin sulfate, sug gesting that this moiety may be required to confer metastatic potential.

34. GÜNTHERT U, HOFMANN $M$, RUDY W, REBer S, ZOUFR $M$ -. Haussmann I, Matzku S, Wenzel A, Ponta P, Herruch P. A New Variant of Glycoprotein CD44 Confers Metastatic Potential to Rat Carcinoma Cells. Cell 1991, 65:13-24.

Perhaps one of the most compelling studies implicating a specific molecule in a causal way in the regulation of tumor metastasis. Although the mechanism by which this spliced variant of CD44 exerts its effect is unclear, these studies highlight the need to explore this experimental system.

35. Elenius $K$, Vainio S, laAto M, Salminta M, Thesleff I: In- duced Expression of Syndecan in Healing Wounds. $J$ Cell Biol 1991, 144:585-595.

An important study that associates increased syndecan expression with the migration and proliferation of epithelial cells during wound heal. ing. This study also notes that expression of syndecan occurs, apparently transiently, in endothelial cells in growing capillaries of granulation tissue.

36. Brittis PA, CANning DR, SILver J: Chondroitin Sulfate as a -. Regulator of Neuronal Patterning in the Retina. Science 1992, 255:733-736

This exciting study provides important new evidence that the temporally regulated patterning of CSPG can serve to control the onset of retinal ganglion cell differentiation and direct initial axonal outgrowth. Clear evidence is presented to show that disruption of the endogenous pattern of CSPG deposition results in ectopic ganglion cell differentiation and disorganization of axonal outgrowth.

37. Perris R, Krotoski D. LaUter T, Domingo C, Sorrell M, - Bronner-Fraser M: Spatial and Temporal Changes in the Distribution of Proteoglycans During Avian Neural Crest Development. Det'lopment 1991, 111:583-599.

This study describes, by histochemical and immunochemical means, changes in distribution of hyaluronan and families of PGs during neu. ral crest migration and gangliogenesis. Most interestingly, of the several general distributions recognized for different PG families, subsets of 6 . sulfated and unsulfated CSPGs were found to be present in prospective neural crest migratory pathways, prior to appearance of the cells, and in areas from which these cells are excluded. This observation supports a general role of these currently incompletely characterized CSPGs in directing cell migration via exclusion mechanisms.

38. FiChaRD A, VERna JM, OLJvares J, SAXOd R: Involvement of a - Chondroitin Sulfate Proteoglycan in the Avoidance of Chick Epidermis by Dorsal Root Ganglia Fibers: a Study Using $\beta$ D-xyloside. Det' Biol 1991, 148:1-9.

This study uses an interesting co-culture system to explore the phe. nomenon of exclusion of contact between elongating neurites and epidermal cells. The experiments implicate soluble chondroitin sulfate chains, which are borne on a yet unidentified CSPG and synthesized by epidermal cells, in forming a barricr preventing innervation by cultured dorsal root ganglia.

39. OOHIRA A, MATSUI F, KATOH-SEMBA R: Inhibitory Effects of - Brain Chondroitin Sulfate Proteoglycans on Neurite Outgrowth from PC 12D Cells. / Neurasci 1991, 11:822-827.

The experiments reported in this study indicate that brain CSPGs may influence neurite outgrowth by the mechanism of inhibition of elonga- 
tion. Unlike other work suggesting that similar inhibitory activity is as. sociated with chondroitin sulfate chains, this work found isolated core proteins from brain CSPGs to be effective inhibitors in their system, and chondroitin chains and cartilage CSPG to be ineffective.

40. EDELBERG M, WeISSLER M, PIZzo SV: Kinetic Analysis of - the Effects of Glycosaminoglycans and Lipoproteins on Urokinase-mediated Plasminogen Activation. Biochem $J$ 1991, 276:785-791.

These kinetic studies indicate that heparin, heparan sulfate and chondroitin-6-sulfate all increase the catalytic rate of the activation of plasminogen by urokinase, which may be involved in migration-related proteolytic events at the cell surface. This work provides, indirectly, an explanation for the mechanism by which PGs might influence cell migration.

41. HineK A, Boyle J, RABINovtTCH M: Vascular Smooth Muscle - Detatchment from Elastin and Migration through Elastin Laminae is Promoted by Chondroitin Sulfate Shedding of the $67 \mathrm{KD}$ Cell Surface Elastin-binding Protein. Exp Cell Res 1992 , in press.

The ability of fetal smooth muscle cells to penetrate an elastin matrix scaffold in culture correlates with reduced expression of elastin recep. tor. The authors found that galactosaminoglycans promoted penetra. tion of the elastin scaffold and speculate that secretion of CSPGs or DSPGs by migrating cells may allow shedding of the elastin receptor and cnhance penetration of elastic laminae.

42. Boudreau N, Turify E, Rabinovtrch M: Fibronectin, Hyaluro- nan and an Hyaluronan Binding Protein Contribute to In creased Ductus Arteriosus Smooth Muscle Cell Migration. Dev Biol 1991, 143:235-247.

This study uses a collagen gel matrix to model migration of ductal cells and aortic fetal smooth muscle cells. Ductal cells specifically respond with increased migration after inclusion of hyaluronan in the gel. The increased migration of these cells in hyaluronan-supplemented gels is blocked by antibodies against a cell surface hyaluronan-binding protein, suggesting an alternative set of receptor-matrix ligands may be operating in hyaluronan-specific migration events.

43. Turley EA, austen L, Vandeugt K, Clary C: Hyaluronan -. and a Cell-associated Hyaluronan Binding Protein Regu. late the Locomotion of Ras-transformed Cells. J Cell Biol 1991, 1041-1047.

Using Ras-transformed cells, driven by a $\mathrm{Zn}^{2+}$.inducible metallothionein promoter, the authors have confirmed that the transient, dramatic stimulation of cell locomotion after ras gene induction is accompanied by a burst of hyaluronan synthesis. Additionally, promotion of ras gene expression induces the synthesis of a complex of hyaluronan-binding proteins, upon which the cells are dependent for locomotion during an initial early phase of hyaluronan-dependent rapid migration.

44. HARDWICK C, HOARE K, OWENS R, HOHN HP, HOOK M, MOORE - D, Cripps V, Austen L, Nance DM, Turley EA: Molecular Cloning of a Novel Hyaluronan Receptor that Mediates Tumor Cell Motility. J Cell Biol 1992, 117:1343-1350.

This study describes the cloning of a novel hyaluronan binding com ponent, which is part of a Ras-induced complex of cell surface binding proteins involved in hyaluronan-mediated motility. This protein, despite its ability to bind hyaluronan, apparently does not contain a domain homologous to the hyaluronan binding domain present in aggrecan, link protein, versican and CD44. The lack of a transmembrane domain suggests that this molecule is associated with other cell surface proteins.

45. WRIGHT TC, CASTELLOT JJ, KaRNOVSKY MJ: Regulation of Cellular Proliferation by Heparin and Heparan Sulfate. In Hep arin Edited by Lane DA, Lindahl U. London: Edward Amold; 1989:295-316

46. Kimura K, Matsubara H, SOgoh S, KrTa Y, Sakata T, NishitanI - Y, watanabe S, hanaoka T, Fujnwara H: Role of Glycosaminoglycans in the Regulation of $\mathrm{T}$ Cell Proliferation Induced by Thymic Stroma-derived T-cell Growth Factor. $J$ Immunol 1991, 146:2618-2624.

Many studies have indicated that the anti-proliferative effect of heparin is not due to the inactivation of a growth factor. This study argues that a stroma-derived $T$ cell growth factor binds to heparin and is inactivated. This effect appears to be specific because other $T$ cell growth factors (IL-2) are not inactivated by heparin. This paper indicates that suppression of cell proliferation by heparin and HS must involve multi ple mechanisms that depend on the nature of the mitogen and the cell type studied.

47. Fager G, Camejo G, Bondjers G: Heparin-like Glycosamino- glycans Influence Growth and Phenotype of Human Arterial Smooth Muscle Cells in Vitro I. Evidence for Reversible Binding and Inactivation of the Platelet-derived Growth Factor by Heparin In Vitm. Cell Dev' Biol 1992, 28A.168-175 This paper presents indirect evidence that heparin blocks PDGF-stimu. lated proliferation of human arterial smooth muscle cells by binding to and inactivating serum mitogens. Other studies using different sources of arterial smooth muscle cells indicate that heparin has no effect on PDGF binding to its receptor. These differences need to be reconciled.

48. WESTERGREN-THORSSON G, ONNERVIK P-Ö, FRANSSON L-Ä, - Malmstrom A. Proliferation of Cultured Fibroblasts is Inhibited by L-iduronate-containing Glycosaminoglycans. J Cell Physiol 1991, 147:523-530

A careful comparison of the effect of different GAGs on the inhibition of proliferation of human lung fibroblasts. The authors conclude that GAG structure (i.e. sulfation and percentage iduronate) and plating density are determining factors for this anti.proliferative activity.

49. FEDARKO NS, CONRAD HE: A Unique Heparan Sulfate in the Nuclei of Hepatocytes: Structural Changes with the Growth State of the Cell. J Cell Biol 1986, 102:587-599.

50. ISHIHARA $M$, CONRAD HE: Correlations between Heparan Sulfate Metabolism and Hepatoma Growth. J Cell Physiol 1989, 138:467-476.

51. Wright TC, Pukac LA, Castelot JJ, Karnovsky MJ, LeVine RA KIM-PARK HY, CAMPISI J: Heparin Suppresses the Induction of $c-f o s$ and $c-m y c$ mRNA in Murine Fibroblasts by Selective Inhibition of a Protein Kinase $\mathrm{C}$ Dependent Pathway. Proc Natl Acad Sci USA 1989, 86:3199-3203.

52. PUKAC LA, Castellot JJ, WRight TC, Caleb BL, KarnovskY MJ: Heparin Inhibits $c$-fos and c-myc Expression in Vascular Smooth Muscle Cells. Cell Regul 1990, 1:435-443.

53. BUSCH SJ, Matin GA, BaRnhaRT RL, MaNo M, CaRDiN -. AD, JACKSON RL. Trans-repressor Activity of Nuclcar Gly. cosaminoglycans on Fos and Jun/AP-1 Oncoprotein-mediated Transcription. I Cell Biol 1992, 116:31-42

A provocative study that uses transient transfections and DNA-binding assays to demonstrate that heparin blocks AP.1-mediated gene expres. sion by forming a complex with Fos.Jun/AP-1 transcription factor. Such observations have important implications for the role of GAGs in dif ferentiation and support the hypothesis that matrix molecules may reg ulate gene activity at nuclear sites.

54. Price kH, Chol HU, Rosenberg I, Staniey ER: The Predom- inant Form of Secreted Colony Stimulating Factor-1 is a Proteoglycan. J Biol Chem 1992, 267:2190-2199.

Evidence that one of the monomeric subunits of CSF-1 contains a CS chain. One of the first mitogens to have been identified as a PG. The biological significance of CSF.1 as a PG needs to be established. An interesting discussion of why the higher molecular weight structure has not been recognized earlier is presented.

55. GORDON MY, RILEY GP, WATT MF: Compartmentalization of a Haematopoietic Growth Factor (GM-CSF) by Glycosaminoglycans in the Bone Marrow Microenvironment Nature 1987, 326:403-405.

56. Roberts R, GallaGher J, SPOONCER E, Aluen TD, BLODMField F, DEXTER TM: Heparan Sulfate Bound Growth Factors: a Mechanism for Stromal Cell Haemopoiesis. Nature 1988. 332:376-378.

57. SakaguChI K, YanagishITA M, TAKeUCHI Y, AURBaCH GD; Iden- tification of Heparan Sulfate Proteoglycans as a High Affinity Receptor for Acidic Fibroblast Growth Factor (aFGF) in a Parathyroid Cell Line. J Biol Chem 1991, 266:7270-7278.

Characterization of a parathyroid cell $150 \mathrm{kD}$ receptor for acidic FGF rcveals that it bears a heparan sulfate chain that is critical for high-affinity binding. These results indicate that cell surface HSPGs differ in their 
binding affinities for different growth factors although the significance of these differences needs to be elucidated.

58. YAYON A, KIAGSBURN M, EsKo JD, Leder P, ORNITZ DM: Cell Surface, Heparin-like Molecules Are Required for Binding of Basic Growth Factor to Its High Affinity Receptor. Cell 1991, 64:841-848.

59. GTra-Goren H, SOKer S, Vlodavsky I, Neufeld G: The Bind- ing of Vascular Endothelial Growth Factor to Its Receptors is Dependent on Cell Surface Associated Heparin-like Molecules. J Biol Chem 1992, 267:6093-6098.

Another study that illustrates the importance of cell surface associated heparin-like molecules in the binding of a growth factor to its highaffinity receptor. The potential significance of this interaction in the regulation of angingenesis needs to be explored

60. PRestrelski SJ, FOX FM, ARAKAWA T: Binding of Heparin to - Basic Fibroblast Growth Factor Induces a Conformational Change. Arch Biochem Biophys 1992, 293:314-319.

This paper identifies highly reproducible and localized conformational changes in bFGF induced specifically by heparin through the use of infrared spectroscopy. Such changes suggest alterations in the number of $\beta$-turns. It remains to be shown whether these alterations influence high-affinity binding of $b F G F$ to its receptor.

61. Rapraeger AC, Krufka A, Olwin BB: Requirement of Hep. - aran Sulfate for bFGF-mediated Fibroblast Growth and Myoblast Differentiation. Science 1991, 252:1705-1798.

Documentation that the presence of HSPG on the surface of cells is critical for bFGF binding and subsequent cellular activation. These studies illustrate the importance of cell surface HSPG in bFGF-directed skeletal muscle differentiation and proliferation of 3 T 3 cells. This system should allow identification of the specific HSPGs involved.

62. Turnbul JE, Fernig DG, Ke Y, Wilkinson MC, Gallagher JT: -. Identification of the Basic Fibroblast Growth Factor Binding Sequence in Fibroblast Heparan Sulfate. J Biol Chem 1992, 267:10337-10341.

A valuable report on the characterization of the oligosaccharide struc. ure of HS required for binding to bFGF. This report indicates that specific binding sequences are present in segments of particular GAG chains. This may be another example in which particular sequences within polysaccharides interact with proteins such as previously demonstrated for the binding of heparin to antithrombin III.

63. CheifETZ S, MASSAGUÉ J: Transforming Growth Factor- $\beta$ (TGF- $\beta$ ) Receptor Proteoglycan. Cell Surface Expression and Ligand Binding in the Absence of Glycosaminoglycan Chains. I Biol Chem 1989, 264:12025-12028.

64. ANDRes JL, RONnStrand L, Chelfetz S, Massague J: Purifica- $\quad$ tion of the Transforming Growth Factor - $\beta($ TGF- $\beta$ ) Binding Proteoglycan $\beta$-glycan. J Biol Chem 1991, 266:23282-23287. Confirmation that $\beta$.glycan exists in tissue and has similar properties to the form identified on the surface of cultured cells.

65. ANDres JL, De Falcis D, Noda M, Massaglé J: Binding of - Two Growth Factor Families to Separate Domains of the Proteoglycan Betaglycan. J Biol Chem 1992, 267:5927-5930. The first demonstration that two different growth factors can bind to the same PG by different mechanisms. These in t'itro observations have implications regarding possible roles that the PG may play in the coordinate regulation of two growth factors (TGF. $\beta$ and bFGF), which have frequently been shown to demonstrate antagonistic activities.

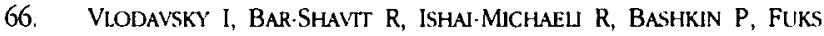
-. Z: Extracellular Sequestration and Release of Fibroblast Growth Factor: a Regulatory Mechanism. Trends Biochem Sci 1991, 16:268-271.

An excellent minireview on the expanding area of interest concerning the interaction of growth factors with PGs present on the surface of cells and within the ECM.

67. Saksela O, Moscattew D, SOmmer A, Rifkin DB: Endothelial Cell-derived Heparan Sulfate Binds Basic Fibroblast Growth
Factor and Protects it from Proteolytic Degradation. J Cell Biol 1988, 197:743-751.

68. Brunner G, Gabrilove J, Rifkin DB, Wilson ET: Phospho- lipase C Release of Basic Fibroblast Growth Factor from Human Bone Marrow Cultures as a Biologically Active Complex with a Phosphatidylinositol-anchored Heparan Sulfate Proteoglycan. J Cell Biol 1991, 114:1275-1283.

One of a number of recent papers demonstrating that PGs can associate with the surface of some cells via a phosphotidylinositol anchor in the plasma membrane. This phosphatidylinositol-associated HSPG binds bFGF and this complex can be released as a biologically active form by phospholipase $C$. This mechanism, together with the prote. olytic cascade of plasminogen activation and plasmin ECM degradation, may generate bFGF-HSPG bioactive complexes and explain regulated control of growth factor release from the ECM.

69. RIFKN DB, MOSCATEU: Recent Developments in the Cell Biology of Basic Fibroblast Growth Factor. J Cell Biol 1989 . 109:1-6.

70. FOLKMAN J, KLAGSBURN M: Angiogenic Factors. Science 1987, 235:442-447.

71. YaMAGUCHI Y, MANN DM, RUOSLAHTI E: Negative Regulation of Transforming Growth Factor- $\beta$ by the Proteoglycan Decorin. Nature 1990, 346:281-284.

72. Vaino S, Jalkanen M, Vanttokari a, Sahlberg C, Mnu M, - BerNFIELD M, THESleff I: Expression of Syndecan Gene is Induced Early, is Transient, and Correlates with Changes in Mesenchymal Cell Proliferation during Tooth Organogenesis. Dev Biol 1991, 147:322-333.

An important study because it confirms the transient expression in mesenchymal cells of a cell surface PG that was once thought to be restricted to the surface of epithelial cells. The significance of selective syndecan expression in the proliferative process needs to be explored.

73. SCHONHERR E, JÄRVELÄINEN HT, SANDEL LJ, W/GHT TN: Ef- fects of Platelet-derived Growth Factor and Transforming Growth Factor- $\beta 1$ on the Synthesis of a Large Versicanlike Chondroitin Sulfate Proteoglycan by Arterial Smooth Muscle Cells. $J$ Biol Chem 1991, 266:17640-17647.

Demonstrates that two growth factors with opposite mitogenic activity cause significant increases in mRNA transcripts for versican. However, only the mitugern alters the sulfation pattern of the CS chain. These post-translational modifications may be characteristic of the proliferative phenotype.

74. Potter-Perigo S, Braun KR, SchonherR E, Wight TN: In- hibition of Cell Proliferation by $\beta$-D-xyloside Can be Dissociated from Altered Proteoglycan Synthesis via the False Acceptor Pathway. Arch Biophys Biochem 1992, 297:101-109. This study addresses the question of whether altered PG synthesis influences the capacity of cells to proliferate. The main conclusion is that the inhibitory effects of some xylosides on cell proliferation must be due to effects other than altered PG synthesis via the false acceptor pathway.

75. GRESSNER AM: Questioning the Reliability of p-nitrophenyl- $\quad \beta$ - D-xyloside as Probe to Study the Metabolic Effects of Abrogated Proteoglycan Synthesis in Cultured Cells. Biochem Pbarmacol 1991, 42:1987-1995.

A study that raises the possibility that some of the biological effects of $\beta$.D-xyloside on cells and tissues are not due to the direct effect of xylosidc on PG synthesis but rather to the aglycone derivative $p$-nitrophenol attached to $\beta$-D-xyloside. Such observations stress the importance of using differently derivated $\beta$-xylosides and appropriate controls to confirm the importance of altered PG synthesis in biological events such as proliferation.

TN Wight, MG Kinsella and E Qwarnström, Department of Pathology, University of Washington, School of Medicine, Seattle, Washington 98195, USA. 